\title{
Chronic Respiratory Symptoms with Normal Spirometry: A Reliable Clinical Entity?
}

\begin{tabular}{|c|c|}
\hline Journal: & American Journal of Respiratory And Critical Care Medicine \\
\hline Manuscript ID & Blue-201607-1376PP.R1 \\
\hline Manuscript Type: & PP - Pulmonary Perspective \\
\hline Date Submitted by the Author: & 25-Aug-2016 \\
\hline Complete List of Authors: & $\begin{array}{l}\text { Rodriguez-Roisin, Roberto; Universitat de Barcelona, Institut Clinic } \\
\text { Respiratori, Hospital Clinic-IDIBAPS } \\
\text { Han, MeiLan; University of Michigan, Division of Pulmonary \& Critical Care } \\
\text { Vestbo, Jørgen; University of Manchester, Centre for Respiratory Medicine } \\
\text { and Allergy } \\
\text { Wedzicha, Jadwiga; Imperial College London, National Heart and Lung } \\
\text { Institute } \\
\text { Woodruff, Prescott; University of California San Francisco, Division of } \\
\text { Pulmonary, Critical Care, Sleep and Allergy, Department of Medicine and } \\
\text { Cardiovascular Research Institute } \\
\text { Martinez, Fernando J; Weill Cornell Medical College }\end{array}$ \\
\hline Subject Category: & Peer Review Office Use Only \\
\hline Keywords: & $\begin{array}{l}\text { Chronic Airway Disease, Exacerbations, GOLD Stage 0, High Resolution } \\
\text { Computed Tomography, Normal Lung Function }\end{array}$ \\
\hline
\end{tabular}




\title{
CHRONIC RESPIRATORY SYMPTOMS WITH NORMAL SPIROMETRY: A RELIABLE CLINICAL ENTITY?
}

\author{
Roberto Rodriguez-Roisin ${ }^{1}$, MeiLan K Han ${ }^{2}$, Jørgen Vestbo ${ }^{3}$, Jadwiga A \\ Wedzicha $^{4}$, Prescott G Woodruff ${ }^{5}$, Fernando J Martinez ${ }^{6}$ \\ 1. Universitat de Barcelona, Institut Clinic Respiratori, Hospital Clínic-IDIBAPS, \\ Barcelona, Spain \\ 2. Division of Pulmonary \& Critical Care, University of Michigan, Ann Arbor, MI, \\ US \\ 3. Centre for Respiratory Medicine and Allergy, University of Manchester, \\ Manchester, UK \\ 4. National Heart and Lung Institute, Imperial College London, London, UK \\ 5. Division of Pulmonary, Critical Care, Sleep and Allergy, Department of \\ Medicine and Cardiovascular Research Institute, University of California San \\ Francisco, CA, US \\ 6. Weill Cornell Medical College, New York, NY, US
}

Words Count: 2,987. Figure/Table: 2

Key Words: Chronic Airway Disease - Exacerbations - GOLD Stage 0 - High

Resolution Computed Tomography- Normal Lung Function

Correspondence: Dr. R. Rodriguez-Roisin. Professor Emeritus of Medicine, Universitat de Barcelona. Institut del Tòrax (Servei de Pneumologia), Hospital ClínicIDIBAPS, Villarroel 170, 08036-Barcelona, Spain. Tel: +34932275404; Fax: +34 932279813; e-mail: rororo@clinic.ub.es. 


\begin{abstract}
(249 words)
\end{abstract}
The 2001 Global Initiative for Chronic Obstructive Lung Disease (GOLD) Report defined five stages of spirometric severity (post-bronchodilator $\mathrm{FEV}_{1} / \mathrm{FVC}$ $\geq 0.7$ ): 0 , and 1 (mild) to 4 (very severe). GOLD Stage 0 was defined by chronic cough and sputum production or chronic mucus hypersecretion $(\mathrm{CMH})$ alone with preserved $\mathrm{FEV}_{1} / \mathrm{FVC}$. Subsequently, GOLD 0 was discarded as further evidence of COPD development in subjects with GOLD 0 was not more likely to develop. When expanding symptomatic burden in GOLD 0 to include other chronic respiratory symptoms, such as dyspnea, wheeze, poor quality of life, limited physical activity, and 'COPD exacerbations-like' events needing health resources, symptomatic smokers with normal $\mathrm{FEV}_{1}$ resulted in larger risk of death. We review the evidence supporting a relationship between an increased symptom burden, long-term $\mathrm{FEV}_{1}$ decline and development of COPD. We also address the evidence for the presence of respiratory symptoms with normal $\mathrm{FEV}_{1}$ in smokers as a potential clinical entity. This subset of symptomatic patients encompasses a compelling category of smokers with normal spirometry but increased risk for poor outcomes. What exactly these symptomatic patients with intact $\mathrm{FEV}_{1}$ represent remains unclear. Whether they exemplify smoking-induced just a broadening of respiratory abnormalities or a distinct clinical entity that precedes the development of COPD or both remains unknown. Other aims, such as providing information on pathogenesis and future areas of research, are just as vital. What ultimately prevails however is the importance of the public health message to the frightening presence of chronic respiratory symptoms in the whole population. 
... "Would you tell me, please, which way I ought to go from here?" "That depends a good deal on where you want to get to." "I don't much care where -" "Then it doesn't matter which way you go."...

'Alice in Wonderland', Lewis Carroll (1832-1898)

The comparison of outcomes between symptomatic individuals with and without chronic obstructive pulmonary disease (COPD) is one of the many research questions posed in a recent American Thoracic Society (ATS)/European Respiratory Society (ERS) Statement ${ }^{1}$ and represents the main thrust of this pulmonary perspective. We review the association between chronic respiratory symptoms, excess decline of $\mathrm{FEV}_{1}$ and development of COPD and the evidence for a potential new clinical entity in individuals with chronic respiratory symptoms and normal spirometry (postbronchodilator $\mathrm{FEV}_{1} / \mathrm{FVC} \geq 0.7$ ). This subset of patients, roughly similar to the group previously labeled 'Stage 0' by the Global Initiative for Chronic Obstructive Lung Disease (GOLD) ${ }^{2}$, suggests a category of symptomatic smokers with normal spirometry but increased risk of poor outcomes. Notwithstanding, it is of note that other functional measures of earlier and more subtle changes in small peripheral airways have been investigated previously. In the 1960s, a large number of studies were devoted to identify susceptible smokers likely to progress to chronic airflow limitation ${ }^{3}$. In the 1970 s, it was observed in young cigarette smokers that inflammation was evident in the small airways in the absence of pulmonary emphysema ${ }^{4}$. A better understanding of the biological mechanisms underlying symptoms in smokers with intact $\mathrm{FEV}_{1} / \mathrm{FVC}$ should improve our ability to treat respiratory symptoms that occur before the development of COPD. 


\section{GOLD 0: SPLENDOR AND DECLINE}

Traditionally, the typical chronic respiratory symptoms of COPD are cough and sputum production, usually referred to as chronic bronchitis or chronic mucus hypersecretion $(\mathrm{CMH})$ (phlegm on most days at least 3 months per year for $2 \mathrm{yrs}$ ). In the past, these were considered common in smokers and strongly related to chronic airflow limitation. In the 1980s, a follow-up study in men concluded that the risk of death from COPD was associated to the initial degree of airflow limitation but not to $\mathrm{CMH}$, supporting that airflow limitation and $\mathrm{CMH}$ were largely independent disease processes ${ }^{5}$. These findings were, however, at variance with data from the Copenhagen City Heart Study (CCHS) cohort showing an association between $\mathrm{CMH}$ and mortality ${ }^{6}$ and analyses of data, at two surveys 5 years apart, that concluded that $\mathrm{CMH}$ was significantly associated with an excess of $\mathrm{FEV}_{1}$ decline ${ }^{7}$.

The first 2001 GOLD Report ${ }^{2}$ stated that a clinical diagnosis of COPD had to be confirmed by spirometry, all values referred to post-bronchodilator $\mathrm{FEV}_{1} / \mathrm{FVC}$. The GOLD document originally defined five spirometric stages (or grades ${ }^{8}$ ): 0 and 1 (mild), 2 (moderate), 3 (severe), and 4 (very severe), a classification also endorsed by the ATS/ERS Task Force for COPD ${ }^{9}$. GOLD 'Stage 0: At Risk', namely the sole presence of chronic cough and phlegm with normal spirometry, offered a unique opportunity to identify individuals at risk for COPD akin to increase awareness among health care providers.

Traditionally, the natural history of COPD has been viewed as synonymous with decline in $\mathrm{FEV}_{1}$ from early adulthood and throughout life following the seminal work by Fletcher and Peto ${ }^{10}$. However, it was acknowledged that most smokers whose $\mathrm{FEV}_{1}$ is 
already below the normal range for non-smokers by early adulthood are at risk of death due to airflow limitation. Alternatively, the majority of smokers whose $\mathrm{FEV}_{1}$ is still above average at this age are unlikely to develop severe airflow limitation. However, recent data from three large cohorts have confirmed that approximately half of the individuals with airflow limitation followed the hypothesis that implied a rapid $\mathrm{FEV}_{1}$ decline within normal limits in early adulthood, whereas the other half had a rather normal $\mathrm{FEV}_{1}$ decline at this age but started from a low initial value of $\mathrm{FEV}_{1}{ }^{11}$, thus supporting the effect of early life events on the likelihood of having airflow limitation in adulthood.

\section{CHRONIC RESPIRATORY SYMPTOMS, LONG-TERM FEV ${ }_{1}$ DECLINE AND $^{2}$ COPD DEVELOPMENT}

In the 2006 GOLD Revision ${ }^{12}$, GOLD 0 was no longer included, as there was incomplete evidence that the individuals who meet GOLD 0 necessarily progress on to GOLD 1+. Nonetheless, the importance of the public health message, to highlight that the presence of cough and sputum in the population is not normal, remained unchanged. GOLD 0 was discarded based on data from the CCHS cohort ${ }^{13}$ in which $7.1 \%$ of men and $4.8 \%$ of women (mean age, over 52 years each) had GOLD 0 at baseline with a prevalence of $6.1 \%$. After 5 and 15 years, COPD developed in $13.2 \%$ and $20.5 \%$ of smokers with GOLD 0 at enrollment, respectively, although symptoms of cough and sputum in unobstructed smokers were associated with an excess lung function decline of $19 \mathrm{ml} / \mathrm{yr}$, in addition to the $\mathrm{FEV}_{1}$ reduction observed in unobstructed smokers without these symptoms. Despite these findings, the data from this study suggested that most of cases of new airflow limitation were observed among subjects without 
symptoms of cough and sputum and, consequently, it was felt that GOLD Stage 0 was of little help in identifying subjects at risk for COPD.

Subsequently, the European Community Respiratory Health Survey Study (ECRHS) ${ }^{14}$ determined that the prevalence of GOLD 0 was $11.8 \%$ in a randomly selected population. Moderate to heavy smoking and second-hand tobacco exposure were significantly associated with GOLD 0 and GOLD 1+. Individuals with GOLD 0 presented the same risks factors, including environmental tobacco exposure and childhood respiratory infections, as those with COPD with similar high percentages of healthcare resources referred to as 'breathing problems'. In a cohort of middle-aged and elderly subjects with GOLD 0 (non-smokers, 21\%), the 10-year incidence of COPD was $13.5 \%{ }^{15}$. Increasing age, smoking and sputum production but not sex, were risk factors for COPD so GOLD 0 appeared to identify individuals at risk for COPD. The study from the large Atherosclerosis Risk in Communities (ARIC) cohort ${ }^{16}$ of smokers and non-smokers brought the novelty that patients with GOLD 0, defined by the association of any chronic respiratory symptom including breathlessness with normal $\mathrm{FEV}_{1}$, had an increased risk of mortality. A parallel study of healthy, middle-aged men, found an association between symptoms and risk of death when widening GOLD 0 definition to subjects with any respiratory symptom (i.e., dyspnea) than those of $\mathrm{CMH}$ alone ${ }^{17}$. A reassessment of the ECRHS cohort alluded to above determined the presence of $\mathrm{CMH}$ and shortness of breath and future occurrence of COPD ${ }^{18}$. It was concluded that the presence of $\mathrm{CMH}$ but not dyspnea identified individuals with a high risk of developing chronic airflow limitation and was considered to be an early marker of COPD regardless of smoking habits. The prevalence of GOLD 0 was $6.2 \%$ in the Proyecto Latinoamericano de Investigación en Obstrucción Pulmonar (PLATINO) study ${ }^{19}$. In 
that study individuals with $\mathrm{CMH}$ had worse lung function and general health conditions with more respiratory symptoms, i.e. wheezing and dyspnea, limited physical activity, 'COPD exacerbations-like' events and use of respiratory medications. In the Tucson Epidemiological Study of Airway Obstructive Disease (TESAOD) ${ }^{20}, \mathrm{CMH}$ at baseline significantly increased the risk for incident airflow limitation and all-cause mortality among individuals younger than 50 years-old, but not among those subjects older than 50 years. The conclusion was that $\mathrm{CMH}$ with preserved $\mathrm{FEV}_{1}$ in the former group may represent an early marker of susceptibility to COPD and all-cause mortality. In the Medical Research Council National Survey of Health and Development (MRC-NSHD), a prospective study of a representative cohort of women and men ${ }^{21}$, the prevalence of $\mathrm{CMH}$ alone among smokers at enrollment increased between ages 36 and 43 from $7.6 \pm 2.0 \%$ to $13.0 \pm 2.6 \%$, respectively. At these ages, the prevalence of $\mathrm{CMH}$ was associated with a higher risk of subsequent airflow limitation with a dynamic, fluctuating pattern subject to decrease after smoking cessation to levels observed in never smokers. Moreover, the longer individuals had symptoms, the higher the FEV 1 decline (Figure 1). The contention was that $\mathrm{CMH}$ in middle-aged smokers may modulate the early phase of COPD development and reflect activity of the chronic airway disease, a hypothesis that was challenged given the background of different clinical and developmental phenotypes ${ }^{22}$.

\section{CLINICAL AND RADIOGRAPHIC CHARACTERISTICS OF SYMPTOMATIC, UNOBSTRUCTED INDIVIDUALS}

Recent data from five large cohorts have characterized the clinical and radiographic features of symptomatic individuals with normal $\mathrm{FEV}_{1}$. From an urban populationbased study ${ }^{23}$, two subsets of current smokers with normal spirometry were randomly 
selected and followed over 3-4 years. In the first group of 59 individuals with normal diffusing capacity ( $\left.\mathrm{DL}_{\mathrm{CO}}\right)$, only 2 subjects $(3 \%)$ developed significant reductions in $\mathrm{FEV}_{1} / \mathrm{FVC}$ and $\mathrm{DL}_{\mathrm{CO}}$. In the second subset with 46 participants with low $\mathrm{DL}_{\mathrm{CO}}$ at baseline, $10(22 \%)$ developed COPD. There were no respiratory clinical and radiographic differences between the two groups.

In the Canadian Cohort of Obstructive Lung Disease (CanCOLD) study ${ }^{24}$, the occurrence of 'exacerbation-like' events in individuals with and without COPD was highlighted. Furthermore, compared with subjects with COPD, those without COPD had half the frequency of exacerbations and were independently associated with several risk factors (i.e., female sex, presence of wheezing, use of respiratory therapies and poor health status). In individuals without COPD, those with exacerbations were more likely to have poorer health-related quality of life and missing social activities than those without exacerbations.

In parallel, the Genetic Epidemiology of COPD (COPDGene) ${ }^{25}$ determined similar acute events of respiratory disease, more common in current and former smokers. In a second study from this same COPDGene cohort, a large sample of unobstructed subjects was compared with patients with GOLD 1+ and also with a cohort of never smokers ${ }^{26}$. One or more of seven pre-defined respiratory-related impairments (i.e., chronic bronchitis, severe respiratory exacerbations, modified Medical Research Council score $\geq 2$, computed tomography (CT) percentage emphysema $>5 \%$ and gas trapping $>20 \%$, St George's Respiratory Questionnaire total score $>25$, and a 6-minute walking distance $(6 \mathrm{MWD})<350 \mathrm{~m}$ ) were observed in $54 \%$ of unobstructed individuals. Never smokers without airflow limitation had worse quality of life and lower physical 
activity and had percentage emphysema or airway-wall thickening on high resolution (HR) CT scan. Current smoking was associated with more respiratory symptoms, although former smokers had more HRCT findings. Advancing age was associated with smoking cessation. Individuals with respiratory impairments were more likely to use common respiratory medication and exhibited worse manifestations. Of note that in the Multi-Ethnic Study of Atherosclerosis (MESA) cohort study ${ }^{27}$, including participants (51\% never smokers) without airflow limitation, emphysema-like lung changes on cardiac CT were associated with all cause mortality among subjects without airflow limitation, particularly among smokers.

Ever or former smokers and never smokers with normal $\mathrm{FEV}_{1}$ from the very recent observational Subpopulations and Intermediate Outcome Measures in COPD Study (SPIROMICS) cohort ${ }^{28}$ were investigated. Chronic respiratory symptoms, based on a COPD assessment test (CAT) cut-off score $\geq 10$, were observed in $50 \%$ of smokers with a prevalence of $\mathrm{CMH}$ of the order of $33 \%$ alone in symptomatic smokers. Importantly, the use of CAT, a questionnaire designed for COPD ${ }^{29}$, provides a broader assessment of symptomatic burden than just respiratory symptoms. Compared with asymptomatic current or former smokers and never smokers, symptomatic smokers were younger and more likely to be current smokers, and reported symptoms of $\mathrm{CMH}$ and a history of wheezing and asthma than those with lesser symptoms (CAT score $<10$ ). Moreover they had significantly less physical activity, slightly lower lung function, more respiratory exacerbations, and HRCT findings consistent with greater airway wall thickening and low percentage emphysema. These differences persisted despite adjustment for reported co-morbidities. There were no differences in the spectrum of symptoms between symptomatic smokers with normal $\mathrm{FEV}_{1}$ and GOLD 1-2 patients. 
Interestingly, the Exacerbations of Chronic Pulmonary Disease Tool (EXACT) Patient Reported Outcome (EXACT-PRO) ${ }^{30}$ approach developed to identify and characterize exacerbations provides a broader conceptual basis than just respiratory symptoms. Finally, the very recent development of the COPD Assessment in Primary Care To Identify Undiagnosed Respiratory Disease and Exacerbation Risk (CAPTURE) tool (Martinez FJ et al., unpublished data) has suggested that a broader concept of symptoms than simple focused respiratory symptoms is useful in identifying undiagnosed COPD. These concepts, including the prominent role of fatigue, may provide some insights into systemic effects of smoking and explain the greater clinical impact identified by recent work on symptomatic, unobstructed smokers than the original GOLD 0 label.

In summary, these data suggest that many individuals with respiratory symptoms but without airflow limitation have CT findings consistent with large airway abnormalities and these individuals experience significant morbidity and increased health care utilization lending credence to the concept that the presence of chronic respiratory symptoms in unobstructed smokers represents a clinically significant entity. The weight of the evidence would suggest that a greater symptom burden, particularly those respiratory in nature, is a risk factor for rapid lung function decline and therefore likely represents one form of early COPD, although this likely only represents one pathway for COPD development as other individuals without symptoms also go on to develop COPD. A study in smokers with GOLD 0-4 from the COPDGene cohort observed a significant association between functional small airways disease, assessed by CTParametric Response Mapping (PRM), that identifies areas of non-emphysematous gas trapping, and $\mathrm{FEV}_{1}$ decline over 5 years ${ }^{31}$. Small airways $(<2 \mathrm{~mm}$ in diameter $)$ are known to be the major site of narrowing in patients with COPD ${ }^{32}$ and disease in the 
small airways is thought to precede the onset of developing emphysematous lesions ${ }^{33}$. While the signal was attenuated in unobstructed individuals as opposed to those with established airflow limitation, CT-assessed small airways disease was still associated with more rapid lung function decline in this group. Notably, however, those unobstructed individuals with excess small airway abnormality were not more symptomatic based on the presence of chronic bronchitis, again reinforcing the multiple trajectories towards the development of airflow limitation. This is further emphasized by data from the Evaluation of COPD Longitudinally to Identify Predictive Surrogate Endpoints (ECLIPSE) cohort study, in which there was no association between $\mathrm{CMH}$ and long-term $\mathrm{FEV}_{1}$ decline whereas the presence of pulmonary emphysema was associated $^{34 ; 35}$.

\section{CLINICAL SIGNIFICANCE AND REMAINING QUESTIONS}

The new data on this clinical condition derived from these cohort studies ${ }^{24 ; 26 ; 28}$ provide valuable insights into this condition as a distinct clinical entity, irrespective of whether it progresses to COPD. This subset of smokers is predominantly observed in middleaged subjects without sex differences. Breathlessness associated with limited physical activity and frequent 'COPD exacerbations-like' events that require respiratory therapies constitute key clinical features. Moreover, it is associated with HRCT percentage airway wall thickness changes. Data from long-term longitudinal clinical studies described above ${ }^{24 ; 26 ; 28}$ suggest that symptoms in unobstructed smokers are associated with higher risk for the future development of airflow limitation, even in the data that ultimately led to the withdrawal of GOLD 0 stage ${ }^{13}$. However, passage through a GOLD 0 stage is not the only pathway to airflow limitation, and many patients with GOLD 0 do not necessarily progress to chronic airflow limitation. 
Whatever the relevance and the robustness of the reported data the list of shortcomings or unmet needs (Table 1) is large and overcome in part the established findings. Of note, however, that in several of these studies ${ }^{26 ; 28}$ cough and phlegm production are not present in all smokers, suggesting that systemic symptoms (i.e., dyspnea. limited physical activity, fatigue) may be more representative of the broad effects of smoking per se. One conclusion is that the full breadth of symptoms associated with early lung disease in smokers has been underestimated and even unrecognized ${ }^{36}$. However, it could also be that e.g. muscles and the cardiovascular system were affected in these smokers. Accordingly, we may probably need to reconsider the strategy of early diagnosis and preventative measures by paying more attention to symptoms. It has been observed that excess mortality in smokers is largely due to associations with diseases, such as renal failure, hypertensive heart disease, and respiratory diseases, not properly caused by smoking ${ }^{37}$.

Alternatively, these unmet needs bring opportunities for future research studies to enhance the understanding of the natural history of COPD while further supporting preventative and therapeutic approaches. According to a retrospective analysis from primary and secondary care cohorts, opportunities to diagnose COPD at an earlier stage are being missed, particularly during the 5 years immediately before diagnosis ${ }^{38}$. These needs extend from the selection of appropriate cohorts of participants between population-based and disease-specific cohorts, including people with risk factors other than tobacco smoking, such as environmental and occupational exposures ${ }^{39}$. A skillful exploitation of tools, such as clinical symptoms (respiratory and non-respiratory) and serum biomarkers ${ }^{40}$ to assess disease activity ${ }^{41}$, including sensitive small airways disease and exercise tests, may be complementary. Likewise, 'COPD exacerbations- 
like' events and coexisting co-morbidities need to be better characterized to provide new insights ${ }^{42 ; 43}$. Furthermore, the different HRCT patterns, combined with novel CT volumetric scans and other imaging novelties, have to be better investigated. The association between endothelial dysfunction, $\mathrm{FEV}_{1}$ and $\mathrm{CT}$ percentage of emphysema in former smokers with normal $\mathrm{FEV}_{1}$ suggests that pulmonary vascular disturbances can be considerably involved in the development of emphysema ${ }^{44}$, which supports the potential role of pulmonary vessels into the pathogenesis of COPD ${ }^{45-47}$. Finally, as in most smokers respiratory and non-respiratory symptoms may come before airflow limitation, we need to reconsider the strategy of early diagnosis and management to give first particular attention to symptoms. Last but not least, pharmacologic and nonpharmacologic therapies to pave the potential of personalized medicine ${ }^{48}$ need also to be re-assessed.

\section{CONCLUSIONS}

It is now time to move beyond GOLD $0^{49}$ to decipher the fundamental question regarding the short- and long-term clinical significance of the presence of chronic respiratory symptoms and preserved lung function. Indeed, the dilemma remains as to whether we are simply confronted with an "early phase" of what will become COPD in the traditional sense or a separate smoking-related condition which is chronic and remains symptomatic without progression to COPD. Indeed it is possible that both patterns occur. Research studies targeting this likely distinct condition in the context of the systemic effects of smoking by itself should shed light for sure on current understanding of the natural history of COPD ${ }^{36 ; 37}$. 


\section{LEGEND TO FIGURE 1}

The estimated $\mathrm{FEV}_{1}$ decline ( $Y$ axis) is influenced by the duration of chronic mucus hypersecretion $(\mathrm{CMH})$ between ages 43 and 60-64 years ( $Y$ axis) calculated for man (A) and woman (B) smokers of average height and weight at age 43. The presence of $\mathrm{CMH}$ on all three occasions was associated with an additional $10.8 \mathrm{ml} / \mathrm{yr} \mathrm{FEV}_{1}$ decline between ages 43 and 60-64 years compared with those without CMH on any occasion (Reproduced by permission from $\operatorname{ref}^{21}$ ). 


\section{Reference List}

1. Celli BR, Decramer M, Wedzicha JA, Wilson KC, Agust + i A, Criner GJ, MacNee W, Make BJ, Rennard SI, Stockley RA, Vogelmeier C, Anzueto A, Au DH, Barnes PJ, Burgel PR, Calverley PM, Casanova C, Clini EM, Cooper CB, Coxson HO, Dusser DJ, Fabbri LM, Fahy B, Ferguson GT, Fisher A, Fletcher MJ, Hayot M, Hurst JR, Jones PW, Mahler DA, Maltais F, Mannino DM, Martinez FJ, Miravitlles M, Meek PM, Papi A, Rabe KF, Roche N, Sciurba FC, Sethi S, Siafakas N, Sin DD, Soriano JB, Stoller JK, Tashkin DP, Troosters T, Verleden GM, Verschakelen J, Vestbo J, Walsh JW, Washko GR, Wise RA, Wouters EFM, ZuWallack RL: An official American Thoracic Society/European Respiratory Society statement: research questions in COPD. European Respiratory Journal 2015; 45: 879-905

2. Pauwels RA, Buist AS, Calverley PM, Jenkins CR, Hurd SS: Global strategy for the diagnosis, management, and prevention of chronic obstructive pulmonary disease. NHLBI/WHO Global Initiative for Chronic Obstructive Lung Disease (GOLD) Workshop summary. Am.J.Respir.Crit Care Med. 2001; 163: 1256-76

3. Macklem PT, Mead J: Resistance of central and peripheral airways measured by a retrograde catheter. J Appl.Physiol 1967; 22: 395-401

4. Niewoehner DE, Kleinerman J, Rice DB: Pathologic changes in the peripheral airways of young cigarette smokers. The New England Journal of Medicine 1974; 291: $755-8$

5. Peto R, Speizer FE, Cochrane AL, Moore F, Fletcher CM, Tinker CM, Higgins IT, Gray RG, Richards SM, Gilliland J, Norman-Smith B: The relevance in adults of air-flow obstruction, but not of mucus hypersecretion, to mortality from chronic 
lung disease. Results from 20 years of prospective observation. Am Rev Respir Dis 1983; 128: 491-500

6. Lange P, Nyboe J, Appleyard M, Jensen G, Schnohr P: Relation of ventilatory impairment and of chronic mucus hypersecretion to mortality from obstructive lung disease and from all causes. Thorax 1990; 45: 579-85

7. Vestbo J, Prescott E, Lange P: Association of chronic mucus hypersecretion with FEV1 decline and chronic obstructive pulmonary disease morbidity. Copenhagen City Heart Study Group. Am J Respir Crit Care Med 1996; 153: 1530-5

8. Vestbo J+, Hurd SS, Agust ${ }^{+} ;$AG, Jones PW, Vogelmeier C, Anzueto A, Barnes PJ, Fabbri LM, Martinez FJ, Nishimura M, Stockley RA, Sin DD, RodriguezRoisin R: Global Strategy for the Diagnosis, Management, and Prevention of Chronic Obstructive Pulmonary Disease. American Journal of Respiratory and Critical Care Medicine 2013; 187: 347-65

9. Celli BR, MacNee W, ERS TF: Standards for the diagnosis and treatment of patients with COPD: a summary of the ATS/ERS position paper. European Respiratory Journal 2004; 23: 932-46

10. Fletcher C, Peto R: The natural history of chronic airflow obstruction. Br.Med J $1977 ; 1: 1645-8$

11. Lange P, Celli B, Agust + i A, Boje Jensen G, Divo M, Faner R, Guerra S, Marott JL, Martinez FD, Martinez-Camblor P, Meek P, Owen CA, Petersen H, PintoPlata V, Schnohr P, Sood A, Soriano JB, Tesfaigzi Y, Vestbo J+: Lung-Function Trajectories Leading to Chronic Obstructive Pulmonary Disease. New England Journal of Medicine 2015; 373: 111-22 
12. Rabe KF, Hurd S, Anzueto A, Barnes PJ, Buist SA, Calverley P, Fukuchi Y, Jenkins C, Rodriguez-Roisin R, van Weel C, Zielinski J: Global Strategy for the Diagnosis, Management, and Prevention of Chronic Obstructive Pulmonary Disease: GOLD Executive Summary. American Journal of Respiratory and Critical Care Medicine 2007; 176: 532-55

13. Vestbo J, Lange P: Can GOLD Stage 0 provide information of prognostic value in chronic obstructive pulmonary disease? Am J Respir Crit Care Med 2002; 166: 329-32

14. de MR, Accordini S, Cerveri I, Corsico A, Sunyer J, Neukirch F, Kunzli N, Leynaert B, Janson C, Gislason T, Vermeire P, Svanes C, Anto JM, Burney P: An international survey of chronic obstructive pulmonary disease in young adults according to GOLD stages. Thorax 2004; 59: 120-5

15. Lindberg A, Jonsson AC, Ronmark E, Lundgren R, Larsson LG, Lundback B: Ten-year cumulative incidence of COPD and risk factors for incident disease in a symptomatic cohort. Chest 2005; 127: 1544-52

16. Mannino DM, Doherty DE, Sonia BA: Global Initiative on Obstructive Lung Disease (GOLD) classification of lung disease and mortality: findings from the Atherosclerosis Risk in Communities (ARIC) study. Respir Med 2006; 100: 115 22

17. Stavem K, Sandvik L, Erikssen J: Can global initiative for Chronic Obstructive Lung Disease stage 0 provide prognostic information on long-term mortality in men? Chest 2006; 130: 318-25 
18. de MR, Accordini S, Cerveri I, Corsico A, Anto JM, Kunzli N, Janson C, Sunyer J, Jarvis D, Chinn S, Vermeire P, Svanes C, ckermann-Liebrich U, Gislason T, Heinrich J, Leynaert B, Neukirch F, Schouten JP, Wjst M, Burney P: Incidence of chronic obstructive pulmonary disease in a cohort of young adults according to the presence of chronic cough and phlegm. Am J Respir Crit Care Med 2007; 175: 329

19. de Oca MM, Halbert RJ, Lopez MV, Perez-Padilla R, Talamo C, Moreno D, Muino A, Jardim JR, Valdivia G, Pertuze J, Menezes AM: The chronic bronchitis phenotype in subjects with and without COPD: the PLATINO study. European Respiratory Journal 2012; 40: 28-36

20. Guerra S, Sherrill DL, Venker C, Ceccato CM, Halonen M, Martinez FD: Chronic bronchitis before age 50 years predicts incident airflow limitation and mortality risk. Thorax 2009; 64: 894-900

21. Allinson JP, Hardy R, Donaldson GC, Shaheen SO, Kuh D, Wedzicha JA: The Presence of Chronic Mucus Hypersecretion across Adult Life in Relation to Chronic Obstructive Pulmonary Disease Development. Am J Respir Crit Care Med 2016; 193: 662-72

22. Lange P, Vestbo J: Chronic Mucus Hypersecretion and the Natural History of Chronic Obstructive Pulmonary Disease. Am J Respir Crit Care Med 2016; 193 : 602-3

23. Harvey BG, Strulovici-Barel Y, Kaner RJ, Sanders A, Vincent TL, Mezey JG, Crystal RG: Risk of COPD with obstruction in active smokers with normal 
spirometry and reduced diffusion capacity. European Respiratory Journal 2015; 46: $1589-97$

24. Tan WC, Bourbeau J, Hernandez P, Chapman KR, Cowie R, FitzGerald JM, Marciniuk DD, Maltais F, Buist AS, O'Donnell DE, Sin DD, Aaron SD, for the CanCOLD Collaborative Research Group: Exacerbation-like respiratory symptoms in individuals without chronic obstructive pulmonary disease: results from a population-based study. Thorax 2014; 69: 709-17

25. Bowler RP, Kim V, Regan E, Williams AA, Santorico SA, Make BJ, Lynch DA, Hokanson JE, Washko GR, Bercz P, Soler X, Marchetti N, Criner GJ, Ramsdell J, Han MK, Demeo D, Anzueto A, Comellas A, Crapo JD, Dransfield M, Wells JM, Hersh CP, MacIntyre N, Martinez F, Nath HP, Niewoehner D, Sciurba F, Sharafkhaneh A, Silverman EK, van Beek EJ, Wilson C, Wendt C, Wise RA: Prediction of acute respiratory disease in current and former smokers with and without COPD. Chest 2014; 146: 941-50

26. Regan EA, Lynch DA, Curran-Everett D, Curtis JL, Austin JH, Grenier PA, Kauczor HU, Bailey WC, DeMeo DL, Casaburi RH, Friedman P, van Beek EJ, Hokanson JE, Bowler RP, Beaty TH, Washko GR, Han MK, Kim V, Kim SS, Yagihashi K, Washington L, McEvoy CE, Tanner C, Mannino DM, Make BJ, Silverman EK, Crapo JD: Clinical and Radiologic Disease in Smokers With Normal Spirometry. JAMA Intern.Med 2015; 175: 1539-49

27. Oelsner EC, Hoffman EA, Folsom AR, Carr JJ, Enright PL, Kawut SM, Kronmal R, Lederer D, Lima JA, Lovasi GS, Shea S, Barr RG: Association between emphysema-like lung on cardiac computed tomography and mortality in persons without airflow obstruction: a cohort study. Ann.Intern.Med 2014; 161: 863-73 
28. Woodruff PG, Barr RG, Bleecker E, Christenson SA, Couper D, Curtis JL, Gouskova NA, Hansel NN, Hoffman EA, Kanner RE, Kleerup E, Lazarus SC, Martinez FJ, Paine R, III, Rennard S, Tashkin DP, Han MK: Clinical Significance of Symptoms in Smokers with Preserved Pulmonary Function. The New England Journal of Medicine 2016; 374: 1811-21

29. Jones PW, Harding G, Berry P, Wiklund I, Chen WH, Kline Leidy N: Development and first validation of the COPD Assessment Test. European Respiratory Journal 2009; 34: 648-54

30. Leidy NK, Wilcox TK, Jones PW, Roberts L, Powers JH, Sethi S: Standardizing measurement of chronic obstructive pulmonary disease exacerbations. Reliability and validity of a patient-reported diary. Am J Respir Crit Care Med 2011; 183: $323-9$

31. Bhatt SP, Soler X, Wang X, Murray S, Anzueto AR, Beaty TH, Boriek AM, Casaburi R, Criner GJ, Diaz AA, Dransfield MT, Curran-Everett D, Galban CJ, Hoffman EA, Hogg JC, Kazerooni EA, Kim V, Kinney GL, Lagstein A, Lynch DA, Make BJ, Martinez FJ, Ramsdell JW, Reddy R, Ross BD, Rossiter HB, Steiner RM, Strand MJ, van Beek EJ, Wan ES, Washko GR, Wells JM, Wendt CH, Wise RA, Silverman EK, Crapo JD, Bowler RP, Han MK: Association Between Functional Small Airways Disease and FEV1 Decline in COPD. Am J Respir Crit Care Med 2016;

32. Hogg JC, Macklem PT, Thurlbeck WM: Site and nature of airway obstruction in chronic obstructive lung disease. N.Engl.J.Med. 1968; 278: 1355-60 
33. McDonough JE, Yuan R, Suzuki M, Seyednejad N, Elliott WM, Sanchez PG, Wright AC, Gefter WB, Litzky L, Coxson HO, Pare PD, Sin DD, Pierce RA, Woods JC, McWilliams AM, Mayo JR, Lam SC, Cooper JD, Hogg JC: Smallairway obstruction and emphysema in chronic obstructive pulmonary disease. The New England Journal of Medicine 2011; 365: 1567-75

34. Vestbo J+, Agusti A, Wouters EFM, Bakke P, Calverley PMA, Celli B, Coxson H, Crim C, Edwards LD, Locantore N, Lomas DA, MacNee W, Miller B, Rennard SI, Silverman EK, Yates JC, Tal-Singer R: Should We View Chronic Obstructive Pulmonary Disease Differently after ECLIPSE? A Clinical Perspective from the Study Team. American Journal of Respiratory and Critical Care Medicine 2014; 189: $1022-30$

35. Vestbo J+, Edwards LD, Scanlon PD, Yates JC, Agusti A, Bakke P, Calverley PMA, Celli B, Coxson HO, Crim C, Lomas DA, MacNee W, Miller BE, Silverman EK, Tal-Singer R, Wouters E, Rennard SI: Changes in Forced Expiratory Volume in 1 Second over Time in COPD. New England Journal of Medicine 2011;

36. Fabbri LM: Smoking, Not COPD, as the Disease. The New England Journal of Medicine 2016; 374: 1885-6

37. Carter BD, Abnet CC, Feskanich D, Freedman ND, Hartge P, Lewis CE, Ockene JK, Prentice RL, Speizer FE, Thun MJ, Jacobs EJ: Smoking and Mortality ГÇö Beyond Established Causes. New England Journal of Medicine 2015; 372: 631-40

38. Jones RC, Price D, Ryan D, Sims EJ, von ZJ, Mascarenhas L, Burden A, Halpin DM, Winter R, Hill S, Kearney M, Holton K, Moger A, Freeman D, Chisholm A, 
Bateman ED: Opportunities to diagnose chronic obstructive pulmonary disease in routine care in the UK: a retrospective study of a clinical cohort. Lancet Respir Med 2014; 2: 267-76

39. Salvi SS, Barnes PJ: Chronic obstructive pulmonary disease in non-smokers. The Lancet 2009; 374: 733-43

40. Agusti AGN, Noguera A, Sauleda J, Sala E, Pons J, Busquets X: Systemic effects of chronic obstructive pulmonary disease. European Respiratory Journal 2003; 21 : $347-60$

41. Agusti A, Vestbo J: Current Controversies and Future Perspectives in Chronic Obstructive Pulmonary Disease. American Journal of Respiratory and Critical Care Medicine 2011; 184: 507-13

42. Beghe B, Verduri A, Roca M, Fabbri LM: Exacerbation of respiratory symptoms in COPD patients may not be exacerbations of COPD. European Respiratory Journal 2013; 41: 993-5

43. Lopez-Campos JL, Agusti A: Heterogeneity of chronic obstructive pulmonary disease exacerbations: a two-axes classification proposal. Lancet Respir Med $2015 ; 3: 729-34$

44. Barbera JA, Riverola A, Roca J, Ramirez J, Wagner PD, Ros D, Wiggs BR, Rodriguez-Roisin R: Pulmonary vascular abnormalities and ventilation-perfusion relationships in mild chronic obstructive pulmonary disease. Am J Respir Crit Care Med 1994; 149: 423-9 
45. Barr RG, Mesia-Vela S, Austin JH, Basner RC, Keller BM, Reeves AP, Shimbo D, Stevenson L: Impaired flow-mediated dilation is associated with low pulmonary function and emphysema in ex-smokers: the Emphysema and Cancer Action Project (EMCAP) Study. Am J Respir Crit Care Med 2007; 176: 1200-7

46. Peinado VcI, Barber+á JA, Ram+;rez J, G+'mez FP, Roca J, Jover Ls, Gimferrer JM, Rodriguez-Roisin R: Endothelial dysfunction in pulmonary arteries of patients with mild COPD. American Journal of Physiology - Lung Cellular and Molecular Physiology 1998; 274: L908-L913

47. Estepar RS, Kinney GL, Black-Shinn JL, Bowler RP, Kindlmann GL, Ross JC, Kikinis R, Han MK, Come CE, Diaz AA, Cho MH, Hersh CP, Schroeder JD, Reilly JJ, Lynch DA, Crapo JD, Wells JM, Dransfield MT, Hokanson JE, Washko GR: Computed tomographic measures of pulmonary vascular morphology in smokers and their clinical implications. Am J Respir Crit Care Med 2013; 188: 231-9

48. Woodruff PG, Agusti A, Roche N, Singh D, Martinez FJ: Current concepts in targeting chronic obstructive pulmonary disease pharmacotherapy: making progress towards personalised management. Lancet 2015; 385: 1789-98

49. Mannino DM, Make BJ: Is it time to move beyond the "O" in early COPD? European Respiratory Journal 2015; 46: 1535-7 


\section{Table 1. Unmet Needs for Research Studies}

- Appropriate population-based cohorts

- Symptoms (respiratory and non-respiratory); serum biomarkers

- Health-related quality of life tools: COPD Assessment Test [CAT]; Exacerbations of Chronic Pulmonary Disease Tool (EXACT) Patient Reported Outcome (EXACTPRO); Saint George's Respiratory Questionnaire [SGRQ]

- Sensitive small airways function and exercise (6 min walking distance; incremental cycle) tests

- COPD 'exacerbation-like’ events: triggers; clinical characteristics; differential diagnosis

- Co-morbidities: cardiovascular; depression; gastroesophageal reflux disease; metabolic; skeletal and muscle

- Computed tomographic (CT) and novel CT volumetric scans and other imaging novelties

- Preventative (smoking cessation; environmental exposures control) and therapeutic (pharmacologic and non-pharmacologic) strategies 
